\title{
ENTRE LUGARES E SUJEITOS DA EJA: MULHERES ERVEIRAS E OS SEUS SABERES CULTURAIS NO VER-O-PESO
}

Louise Rodrigues Campos ${ }^{1}$ Ivanilde Apoluceno de Oliveira ${ }^{2}$

\section{RESUMO}

Objetiva-se, neste texto, discorrer sobre os ensinos e as aprendizagens vivenciadas por cinco mulheres erveiras que trabalham no Ver-o-Peso. Ao tratar-se de lugares da EJA (Educação de jovens e adultos) pontuam-se os cotidianos familiar e de trabalho em que são vivenciados ensinos e aprendizagens e são compartilhados saberes culturais. Diante disso, pondera-se que este trabalho resultou de uma pesquisa de mestrado no Programa de Pósgraduação em Educação da Universidade do Estado do Pará PPGED UEPA, realizada no período de 2018 a 2020. Trata-se de uma pesquisa de campo, com abordagem qualitativa (MINAYO, 2009); observação in loco (MINAYO, 1994) e entrevistas semiestruturadas. $\mathrm{Na}$ sistematização e na análise dos dados foram construídas categorias analíticas e temáticas (OLIVEIRA; MOTA NETO, 2011). A construção das categorias teve como referência técnicas da análise de conteúdo, (BARDIN, 2011). Diante disso, a pesquisa indicou os seguintes resultados: no processo de manipulação das ervas medicinais destaca-se a conexão entre corpo e mente, nos momentos saber identificar, diferenciar e combinar raízes, cascas e suas propriedades medicinais, pela textura, pela cor, pelo aroma e pelo formato. Os

\footnotetext{
${ }^{1}$ Mestra em Educação (PPGED-UEPA). Licenciada Plena em Pedagogia. Pesquisadora do Núcleo de Educação Popular Paulo Freire. ORCID: https://orcid.org/0000-0002-59705553. E-mail: louisercampos8@gmail.com.

${ }^{2}$ Doutora em Educação pela PUC-SP e UNAM/UAM Iztapalapa - México. Pós-doutora em Educação pela PUC- Rio. Docente do Programa de Pós-Graduação em Educação da Universidade do Estado do Pará (PPGED/UEPA). Coordena o Núcleo de Educação Popular Paulo Freire e a Cátedra Paulo Freire da Amazônia. Orcid: https://orcid.org/0000-00023458-584X. E-mail: ivanildeapoluceno@uepa.br.
} 
ensinos e aprendizagens vivenciados por elas ocorrem por meio da oralidade, do registro escrito, da observação e da gestualidade. Assim, os ensinos, as aprendizagens e os saberes constituem as autonomias de ser erveira, referente à memória, à herança familiar e ao sustento material, a partir do trabalho no setor das ervas.

Palavras-chave: Educação de Jovens e Adultos. Saberes Culturais. Mulheres erveiras.

\section{BETWEEN PLACES AND SUBJECTS OF EJA: WOMEN HERB HANDLERS AND THEIR CULTURAL KNOWLEDGE IN VER-O- PESO}

\section{ABSTRACT}

The objective of this text is to discuss the teachings and learning experienced by five women herb handlers, who work at Ver-o-Peso. When dealing with EJA (Youth and Adult Education) places, the family and work routines are highlighted in which teaching and learning are experienced and cultural knowledge is shared. Therefore, it is considered that this work resulted from a master's research in the Postgraduate Program in Education of the State University of Pará PPGED - UEPA, carried out from 2018 to 2020. It is a field research, with a qualitative approach, (MINAYO, 2009); observation in loco (MINAYO, 1994) and semi-structured interviews. In the systematization and analysis of data, analytical and thematic categories were built (OLIVEIRA; MOTA NETO, 2011). The construction of the categories was based on technical content analysis (BARDIN, 2011). Therefore, the research indicated the following results: in the process of handling medicinal herbs, the connection between body and mind stands out, at times knowing how to identify, knowing how to differentiate and combine roots, bark and leaves and their medicinal properties, by texture, by color, by aroma, by shape. The teachings and learning experienced by them occur through orality, written record, observation, and gestures. Thus, teachings, learning and knowledge constitute the autonomy of being 
women herb handlers, referring to memory, family inheritance, and material support, from work in the herb sector.

Keywords: Youth and Adult Education. Cultural Knowledge. Women herb handlers.

\section{ENTRE LUGARES Y TEMAS DE EJA: HERBOLARIAS Y SUS CONOCIMIENTOS CULTURALES EN VER-O-PESO}

\section{RESUMEN}

El objetivo de este texto es discutir las enseñanzas y el aprendizaje experimentado por cinco mujeres herbolarias que trabajan en Ver-oPeso. Cuando se trata de lugares de EJA (Educación de Jóvenes y Adultos), se destacan las rutinas familiares y laborales en las que se vive la enseñanza y el aprendizaje y se comparte el conocimiento cultural. Por lo tanto, se considera que este trabajo es el resultado de una investigación de maestría en el Programa de Posgrado en Educación de la Universidad Estatal de Pará PPGED - UEPA, realizada de 2018 a 2020. Es una investigación de campo, con enfoque cualitativo, (MINAYO, 2009); observación in loco (MINAYO, 1994) y entrevistas semiestructuradas. En la sistematización y análisis de datos se construyeron categorías analíticas y temáticas (OLIVEIRA; MOTA NETO, 2011). La construcción de las categorías se basó en el análisis de contenido técnico (BARDIN, 2011). Por tanto, la investigación arrojó los siguientes resultados: en el proceso de manipulación de las hierbas medicinales se destaca la conexión entre cuerpo y mente, en ocasiones saber identificar, saber diferenciar y combinar raíces, corteza y hojas y sus propiedades medicinales, por textura, color, aroma, forma. Las enseñanzas y el aprendizaje experimentado por ellos ocurren a través de la oralidad, el registro escrito, la observación y los gestos. Así, la enseñanza, el aprendizaje y el conocimiento constituyen la autonomía de ser herbolaria, referida a la memoria, la herencia familiar y el apoyo material, del trabajo en el sector herbáceo. 
Palabras clave: Educación de Jóvenes y Adultos. Conocimiento cultural. Herbolarias.

\section{INTRODUÇÃO}

Neste trabalho, versa-se sobre a dimensão educativa presente nas vivências de cinco mulheres que trabalham com ervas medicinais, no setor das ervas, localizado no complexo do Ver-o-Peso, em Belém do Pará. Dessa forma, objetiva-se discorrer sobre os ensinos e as aprendizagens vivenciadas por mulheres erveiras que trabalham no Ver-o-Peso.

Diante disso, é essencial abordar sobre os protagonismos dessas mulheres, as formas como elas conduzem as suas práticas de trabalho, garantem as suas sobrevivências, vivenciam os cotidianos e espaços de ensinos e aprendizagens, compartilham saberes e expressam as suas leituras de mundo, referente aos modos saberfazer a manipulação de ervas com propriedades medicinais. Elas relataram sobre as atividades de trabalho que desenvolvem no setor das ervas, as relações familiares em suas residências, e as memórias da infância.

Logo, ao se tratar de lugares da EJA, pontuam-se os cotidianos familiar e de trabalho em que são vivenciados ensinos e aprendizagens, bem como compartilhados saberes culturais. E, referente aos sujeitos, o foco consiste nessas mulheres que expressam com os seus corpos e mentes, uma dimensão educativa e afetiva em suas práticas socioculturais, constituídas por memórias, conhecimentos e saberes culturais, que constituem ser erveira e trabalhar no Ver-o-Peso.

Assim, este texto se situa na temática sobre os saberes, ensinos e aprendizagens dos sujeitos adultos, nesse caso, das mulheres que trabalham no Ver-o-Peso e suas leituras de mundo, referente aos cotidianos que elas vivenciam e transformam, a partir das suas relações familiares e de trabalho para a produção de pomadas, sabonetes, essências e banhos de ervas.

Essas mulheres e suas redes de aprendizados, expressados em suas produções, constituem a diversidade de sujeitos e lugares de 
vivências socioculturais e educacionais, essenciais ao tratar-se da Educação de Jovens e Adultos (EJA). Essa entendida como uma construção partilhada com os sujeitos, homens, mulheres, adultos (as), jovens, idosos (as), e suas narrativas de vida, formas de trabalho, de ensinar e aprender.

Diante disso, pondera-se que este trabalho resultou de uma pesquisa de mestrado no Programa de Pós-graduação em Educação da Universidade do Estado do Pará (PPGED - UEPA), realizada no período de 2018 a 2020.

O caminho metodológico foi realizado no setor das ervas, no Ver-o-Peso. Este está localizado na região metropolitana de Belém, no bairro do Comércio, entre a Avenida Boulevard Castilhos França e a Baía do Guajará. O Ver-o-Peso consiste no complexo arquitetônico formado por: dois mercados (de carne e de peixe); feira do açaí; doca de embarcações; duas praças (do pescador e do relógio) e o Solar da beira.

O setor das ervas é organizado em quatro blocos, indicados de $A$ até $D$, com mais de oitenta espaços de $1 \mathrm{~m}$ por $1 \mathrm{~m}$, chamados pelas erveiras de barraca ou banca. Esse setor funciona diariamente, da manhã até início da noite, de modo que os horários e dias de trabalho dependem do cotidiano de trabalho de cada erveira. Há homens e mulheres que trabalham como erveiras (os) neste setor, local onde são comercializados os produtos como perfumes, pomadas, sabonetes, banhos de ervas, óleos, cascas e raízes para chás.

Nesse contexto, referente ao trabalho desenvolvido no setor das ervas no complexo arquitetônico do Ver-o-Peso, foram cinco mulheres que relataram os seus modos de saber-fazer, ensinar e aprender sobre ervas medicinais. Referente à identificação delas, neste texto, corresponderá aos seguintes nomes fictícios: Aloe Vera; Erva-doce; Andiroba; Camomila e Copaíba. Elas contaram as suas experiências no trabalho no setor das ervas, a partir das suas trajetórias de vida, em que há memórias familiares, formas de sobrevivência de si e das suas famílias, os seus ensinos e aprendizagens.

A pesquisa realizada consistiu em uma abordagem qualitativa, referente às significações que as erveiras atribuem às formas de 
ensino e aprendizagem que perpassam a sua dinâmica de trabalho, visto que esta abordagem valoriza:

as múltiplas histórias que por um momento relativizam a "grande história" pátria dos livros oficiais, são descobertas como instâncias de um cotidiano de "gente como a gente". Pessoas, seres humanos que criam a vida que vivem, que vivem e pensam as suas próprias histórias que elas têm, de fato, um sentido; histórias pessoais e coletivas de vida que desvelam pessoas e grupos humanos (BRANDÃO, 2003, p. 91).

No que se refere aos procedimentos metodológicos foram realizadas entrevistas do tipo semiestruturada, de forma individual com as erveiras no setor das ervas, a fim de investigar como ocorre o processo de trabalho com as ervas, as etapas, e como ensinaram/ensinam e aprenderam/aprendem.

Entende-se que esse tipo de entrevista "parte de um roteiro pré-estabelecido, mas, na sua aplicação, o entrevistador pode acrescentar novas perguntas, conforme o teor da narrativa do entrevistado." (OLIVEIRA; FONSECA; SANTOS, 2010, p. 46).

Antes das entrevistas ocorreram momentos de diálogos com os sujeitos em que foi explicada a pesquisa e acordados os detalhes sobre a participação, mediante a apresentação do Termo de Livre Consentimento Esclarecido (TCLE), conforme cuidados éticos da pesquisa.

Acerca da sistematização e da análise dos dados, foram construídas categorias analíticas e temáticas. As categorias analíticas são construídas a partir do referencial teórico e vão auxiliar na reflexão crítica das informações (OLIVEIRA; MOTA NETO, 2011). As categorias temáticas são construídas a partir da coleta de dados e se caracterizam do seguinte modo:

constituem o que denominamos de indicadores de análise, ou seja, fatores, aspectos, elementos do fato ou situação em estudo, que são classificados e reunidos em eixos ou unidades temáticas a partir e com os dados coletados. Essas unidades temáticas podem ser subdivididas para organização dos 
dados. As categorias temáticas podem ser organizadas a partir de palavras-chave, de ideias fundantes ou de temas que aglutinam determinadas informações (OLIVEIRA; MOTA NETO, 2011, p. 164).

A construção das categorias tem como referência técnicas da análise de conteúdo, com o agrupamento de conceitos, elementos a partir de suas relações, das características em comum que apresentam (BARDIN, 2011). A partir da organização dos dados coletados emergiram os temas autonomia de ser erveira; saber-fazer e ensinar-aprender.

\section{SER ERVEIRA: trajetórias das mulheres que trabalham no Ver- o-Peso}

Nas trajetórias de vida de cada uma das mulheres que compõem esse texto, há os tempos de experiência delas no Setor das ervas (Aloe Vera, trinta e dois anos, Erva-doce, quarenta e seis anos, Andiroba, cinquenta anos, Camomila, quinze anos e Copaíba, vinte e um anos). Esses tempos compõem a memória e a história dos trezentos e noventa e dois anos de existência do Ver-o-Peso.

Essas mulheres não somente se integram ao Ver-o-Peso, mas também o transformam e são transformadas, a partir das relações econômicas, familiares, de ensino aprendizagem, de amizades, dentre outras, que elas tecem com esse lugar. Relações essas que dizem respeito ao que representa ser erveira, que corresponde às suas memórias, às suas compreensões de mundo, às suas formas de sobrevivência e às suas sabedorias.

Desse modo, sobre ser erveira foi ressaltado o ato de conhecer as ervas para o preparo dos remédios naturais, de modo que "é onde eu me identifico, com os meus conhecimentos de remédio" (Erva-doce). Além disso, foi possível observar a expressão ser erveira referente ao íntimo, à alma, à conexão com a natureza, como assinalado pela Aloe Vera:

a gente vem predestinada para tua profissão. Eu escolhi as ervas. Quando eu casei e ganhei essa barraca. Quando eu comecei a trabalhar aqui eu vi é 
isso que eu quero, porque eu gosto muito de ervas. Eu sou mato! Eu sou terra, eu gosto do cheiro de mato, eu gosto do cheiro de sementes, de raízes. Se dependesse de mim eu só comia ervas, verduras e legumes. Eu comeria só sementes, raízes e folhas. Eu me alimentaria só disso! É algo do meu interior, do meu íntimo, da minha alma. Eu gosto de tomar banho de cheiro; banho de descargo, tanto faz eu estar feliz ou de cabeça baixa. Eu gosto muito de banho, de canela, de cravinho, de louro, eu gosto de tudo que é folha, raiz. Eu sou apaixonada pelas ervas! Eu sou apaixonada por tudo o que vem debaixo da terra! Eu faço defumação na minha casa, eu gosto de passar as essências na casa (ALOE VERA).

Ela demonstra a sua conexão com a natureza, mediante à afetividade que ela tem pelos recursos naturais e pelo que é possível criar e utilizar a partir desses materiais, como os banhos feitos a partir das folhas e raízes, como as defumações, as essências de cada erva. Acerca disso, observa-se o termo ser erveira entendido como uma profissão e também como parte do próprio sujeito, como no caso da Aloe Vera, ao afirmar que se trata do seu íntimo. Ela pontou a afetividade quanto a ser erveira.

Além disso, ser erveira foi ressaltado por ela referente às suas práticas cotidianas, como banhar-se de cheiro, além do seu cotidiano de trabalho com a manipulação e comercialização dos produtos naturais no Ver-o-Peso. Sobre o trabalho, foram destacadas a questão financeira e sustento familiar, pois:

eu nunca pensei na minha vida que eu ia ser erveira, porque eu vinha pra cá via a minha avó trabalhando e eu nem me dedicava, só ficava olhando, mas quando chegou uma época que eu vim pra cá trabalhar, fiquei grávida e vim trabalhar aqui aí eu gostei em termo de trabalho, de ter o meu dinheiro, trabalhei e adorei e eu adoro trabalhar aqui, tenho muito orgulho! (ANDIROBA).

É orgulho, e através daqui que eu pago os meus compromissos, as minhas dívidas e o estudo do meu filho, junto com o meu marido pra gente dar uma boa 
educação pra ele. Então eu tenho orgulho (CAMOMILA).

Nesse contexto, vê-se a autonomia da mulher, acerca da sua profissão, de realizar o seu trabalho. Além disso, o trabalho como erveira no Ver-o-Peso está associado às diferentes dimensões da vida dessas mulheres, os quais ocorreram em momentos, como:

foi quando eu fiquei desempregada, eu parei de trabalhar na área de saúde e vim pra cá, porque logo em seguida eu passei no vestibular. Daqui eu pagava a minha faculdade há quinze anos atrás. Eu não podia ficar de dependência em nenhuma matéria, tinha que passar mesmo, nem tinha tempo para estudar. Ainda tinha que fazer estágio. $E$ associar à minha vida de casada, filho, mulher, mãe, tinha hora que dava até vontade de desistir. Estudando e trabalhando, mas é assim mesmo, é com luta que vem a vitória-(CAMOMILA).

Nota-se que essas rotinas de estudo e trabalho, estão articuladas a dimensões como ser mãe, realizar uma formação acadêmica e ter uma renda, mediante as seguintes explicações:

porque isso é tudo, meu trabalho, é como eu me sustento, é como eu levo o meu dia-a-dia, eu pago as minhas contas. E a minha formação foi a partir daqui que eu consegui pagar faculdade e eu quero pagar para o meu filho (CAMOMILA).

é uma renda, porque daqui eu ajudo na minha casa, ajudei meus filhos, ajudei a pagar faculdade do filho, ajudei a pagar o colégio da minha neta (ERVADOCE).

Essas experiências de ensino e aprendizagem delas, sobre a manipulação de ervas medicinais, e trabalharem nesse âmbito está atravessado por questões socioeconômicas, culturais e históricas, como ser mulher, mãe, profissional, conhecedora e sábia no campo da saúde, referente às ervas com propriedades medicinais.

As rotinas de estudo e trabalho que são desenvolvidas por essas mulheres como forma de sobrevivência material, sustento 
familiar e resistência, decorre de objetivos, como, por exemplo, concluir uma formação acadêmica, conforme ressaltado a seguir:

Eu estava fazendo pedagogia, parei no quinto semestre. Pretendo abrir agora dia 20 de novembro, retornar que falta dois semestres para eu terminar. Eu quero fazer o meu TCC (Trabalho de Conclusão de curso) a respeito das ervas, acho que seria muito legal (ERVA-DOCE).

Nesse relato, ela afirma o seu protagonismo e dos seus saberes sobre ervas medicinais, no âmbito institucional acadêmico. Referente a isso, entende-se que os sujeitos ocupam os espaços educacionais, como as escolas e universidades, com as suas leituras de mundo, os conhecimentos construídos nos contextos históricos e socioculturais que vivenciam, em que compartilham saberes, ensinam e aprendem, visto que:

vivemos e construímos nossas aprendizagens entre culturas, embebidos por essa diversidade que nos afeta e nos constitui. Precisamos perfilhar que os alunos e alunas da EJA, possuem patrimônios culturais relacionados às suas narrativas, suas vidas em comunidades, aos grupos sociais a que pertencem, ao contexto em que vivem (FELDMANN; NUNE; MIRANDA, 2020, p. 161).

Portanto, foram assinalados fatores como o sustento familiar a partir do trabalho, vivenciado de forma geracional, afetividade, orgulho, ter conhecimento sobre ervas medicinais, e a conquista de objetivo, como uma formação acadêmica. Sobre isso, foi pontuado que ser erveira representa:

pra mim é tudo. Tudo na minha vida. Por isso, quando alguém me pergunta: "o que você faz? Qual a sua profissão?" eu digo que eu sou feirante. Eu sou erveira, trabalho com ervas medicinais, tratando das pessoas no Ver-o-Peso (ERVA-DOCE)

pra mim é tudo, no financeiro, como de bem estar, felicidade. Ela me preenche. Eu me vejo ficar velhinha 
vendendo ervas, igual a minha avó, minha bisavó, minha mãe (COPAÍBA).

Percebe-se que além dos fatores financeiros e de bem-estar, a relação familiar, conforme demonstrado na afirmação da Copaíba, referente à profissão de erveira realizada de forma geracional. Essa influência familiar sobre a prática de trabalho no Ver-o-Peso, diz respeito às condições sociais que compõem as trajetórias de vida desses sujeitos, de sobrevivência, persistência e de ensinos e aprendizagens, acerca das ervas com propriedades medicinais. Por isso, tratar-se dos modos de saber-fazer dessas mulheres está entrelaçado às suas trajetórias de vida.

Destarte, trabalhar como erveira constitui a autonomia de ser erveira, mas ser erveira não se trata somente das atividades de trabalho, como no caso do ensino e aprendizagem vivenciado, com o objetivo de compartilhar-se e dar continuidade a um legado de conhecimentos correspondentes a uma mesma família.

Concernente a isso, a autonomia de ser erveira diz respeito a um processo contínuo, para além do que é produzido, condiz com as experiências que essas mulheres vivenciam ao manipularem as ervas com propriedades medicinais; é referente aos potenciais criativos delas, aos seus saberes, às suas memórias, às suas lógicas e compreensões de mundo, quanto à saúde e bem-estar.

\section{OS COTIDIANOS DE ENSINOS E APRENDIZAGENS DAS ERVEIRAS}

A respeito dos ensinos e aprendizagens, ressaltou-se a forma geracional com que estes são compartilhados. Sobre esse modo de ensino e aprendizagem, pelas famílias que trabalham no setor das ervas, observou-se com frequência a participação materna, o que demonstrou um protagonismo dessa participação nos processos de ensino e aprendizagem vivenciados pelas erveiras, como presente no seguinte relato:

pra mim é muito gratificante tudo o que eu aprendi. Aprendi com a minha mãe os conhecimentos. Eu devo muito a ela. Tudo o que eu sei, o que eu aprendi, 
devo a minha mãe. Então, para mim é gratificante trabalhar aqui (ERVA-DOCE).

$\mathrm{Na}$ sua fala os atos de aprender, conhecer e saber, relacionados à sua atividade de trabalho consistem no ensino e na aprendizagem que ela vivenciou com a mãe. A respeito dos processos de ensino e aprendizagem, construídos por meio das relações de parentesco, entende-se que estes consistem em modos culturais com que cada grupo familiar ensina e aprende, compartilha conhecimentos, saberes e segredos que os familiares dão continuidade de forma semelhante ou criativa, em que recriam, modificam o que foi ensinado e aprendido, de modo que:

nas famílias, a aprendizagem e o desenvolvimento ocorrem nas próprias relações cotidianas, através de observações, atividades rotineiras realizadas em conjunto, padrões de interação progressivamente mais complexos presentes nessas atividades, afetividade, equilíbrio/ desequilíbrio de poder e valores presentes nas relações interpessoais entre os membros do contexto familiar. Por fim, cabe destacar que apesar de todos os grupos familiares apresentarem valores, hábitos, mitos, pressupostos, formas de sentir e de interpretar o mundo que são transmitidos através das gerações, tais aspectos mostram-se arraigados a uma cultura familiar própria, em que cada família apresenta peculiaridades e padrões interacionais específicos (GARCIA et al., 2007, p. 97).

Quanto à profissão de erveira, também se observou a influência do convívio familiar, como relatou Camomila ao destacar que conviveu, ao longo dos anos, com esta profissão na família, pois observava o avô, que manipulava produtos naturais para o tratamento da saúde, inclusive trabalhava no Ver-o-Peso. Por isso, ao versar sobre a sua profissão, ela destacou que:

sobre ser erveira está no meu sangue, porque eu tenho opção, eu me formei e até agora ainda estou aqui. Desde criança eu já convivi com o meu avô, com a minha mãe. Eles fazendo os chás em casa $e$ 
trabalhando aqui na feira, desde pequena. Eu já cresci com isso, minha mãe fazendo chá, meu avô e foi evoluindo até hoje, que sou eu. Eu faço em casa (CAMOMILA).

então, como eu me identifico é porque está no meu sangue, é herança e até hoje ainda estou aqui, mesmo tendo opção para trabalhar em outra coisa (CAMOMILA).

Ela demonstra que dá continuidade a essa profissão, que faz parte da sua história de vida, em razão de conviver desde a sua infância com a prática cotidiana do seu avô e da sua mãe de fazerem chás em casa. A Camomila, ao evocar essa lembrança da infância, evidencia a relação entre o passado e o presente dela, ao conviver com a sua mãe e o seu avô fazendo os chás 'até hoje', e se tornar, então, a pessoa quem prepara os chás. O vínculo familiar expressado por sua lembrança da infância dá sentido ao trabalho que ela realiza no presente, ou seja, a prática de manipular remédios naturais está integrada ao passado, por meio dessa memória, pois:

um desejo de explicação atua sobre o presente e sobre o passado, integrando suas experiências nos esquemas pelos quais a pessoa norteia a sua vida. O empenho do indivíduo em dar sentido à sua biografia penetra as lembranças com um 'desejo de explicação' (BOSI, 1994, p. 419).

Assim, Camomila, ao falar de sua profissão como erveira, explica o sentido do trabalho que realiza hoje, a partir de sua lembrança no convívio familiar. Esse tempo em família que ela vivenciou no passado, ao observar os seus familiares fazerem os chás em casa, está relacionado ao tempo presente que ela vivencia aos prepará-los, de modo que esses momentos vividos por ela compõem a memória da sua profissão como erveira.

Entende-se que a memória referente à profissão de erveira não é somente um passado, o que já foi vivido. Mas essa memória compõe um entremeio entre tempos - passado e presente -, que diz respeito às lembranças do convívio familiar, que envolveu o preparo de chás, dentre outros remédios naturais feitos em casa, o qual diz 
respeito ao tempo atual, na realização do trabalho como erveira no Ver-o-Peso.

Dessa forma, referente à relação entre memória e aprendizado, foi enfatizado o vínculo familiar por meio de diferentes gerações que trabalharam na mesma profissão, pois:

sobre as ervas, foi a minha bisavó que trouxe o meu avô. O meu avô trouxe a minha mãe e a minha mãe me trouxe e eu estou aqui. A minha bisavó morreu com 110 anos, eu ainda conheci ela. É de família. Eu tenho muito orgulho, porque eu aprendi, veio de família, da minha bisavó. Sempre trabalhei na mesma barraca, eu trabalhei com a minha tia, vim trabalhar com ela e aprendi (ANDIROBA).

Posto isso, além dos aprendizados em família, a partir de mãe, tia, avô e bisavó que trabalharam como erveiras (o), também foi ressaltado o aprendizado no âmbito familiar, referente aos outros ofícios, como os de benzedeira e parteira, presente na fala da Aloe Vera, sobre o seu contato com produtos naturais, como chás, que ocorreu da seguinte forma:

como a minha mãe era benzedeira e parteira eu aprendi muitas coisas com ela. Eu fui criada tomando chá, garrafada. Se estava com dor de cabeça, fazia um banho. Sempre com remédio caseiro, produtos naturais (folhas, sementes, cascas, raízes) (ALOE VERA).

Observa-se a participação da mãe no aprendizado da filha. Ademais, vê-se que o aprendizado da Aloe Vera, caracterizou-se como um processo de experienciar os conhecimentos sobre os produtos naturais no seu cotidiano, ou seja, praticar os banhos, tomar os chás e as garrafadas.

Desse modo, a afirmação dela, a qual mostra que passou a conhecer os remédios naturais ao tomar os que a sua mãe preparava, demonstra a experiência no sentido do que nos acontece, ao entender-se que "é a experiência aquilo que 'nos passa', ou que nos toca, ou que nos acontece, e ao nos passar nos forma e nos transforma (BONDÍA, 2002, p. 26). 
No acontecer, descrito pela Aloe Vera, ela e a mãe tratavam das doenças que o corpo expressava, ao mesmo tempo em que vivenciavam o ensino e a aprendizagem sobre a potencialidade das folhas, cascas, raízes e sementes para a saúde e o bem-estar. A relação entre Aloe Vera e a mãe, sobre as práticas de manipular remédios naturais, consistiram em um cotidiano de ensino e aprendizagem, sobre saber-fazer o banho, saber o modo como banhar-se e a potencialidade deste para atender aos anseios das pessoas, como, por exemplo, atrair sucesso ou afastar sentimentos indesejados. Por isso, no relato da Aloe Vera sobre as suas vivências, compreende-se um banhar-se de aprender. Essa expressão caracteriza um modo de aprender que tem o seu sentido de ocorrer relacionado à própria vivência do sujeito.

No caso da Aloe Vera, a sua vivência sucedeu por meio da prática de tomar um chá, ou de fazer uso de um banho, para atender ao seu problema de saúde, como a dor de cabeça. $\mathrm{O}$ ato de vivenciar não é só entendido referente ao que é produzido, mas também diz respeito ao modo como se faz um chá, por exemplo, visto que:

\begin{abstract}
ao mesmo tempo em que produzimos materialmente as condições naturais de nossa sobrevivência como pessoas, comunidades, espécie, recriamos a cada momento as condições sociais e simbólicas do exercício da experiência interativa do tornar a sobrevivência uma vivência. E o tornar a vivência uma convivência dotada de valores, de símbolos, de saberes, sentidos e significados. Eis porque dizemos em termos bastante atuais que a cultura está mais no que e no como nós nos dizemos palavras, ideias, símbolos e mensagens entre nós, para nós e a nosso respeito, do que no que nós fazemos em nosso mundo, ao nos organizarmos socialmente para viver nele e transformá-lo (BRANDÃO, 2015, p. 98).
\end{abstract}

Os chás preparados pela Aloe Vera e a mãe correspondem aos modos de preparo-entrelaçados com as condições sociais dessas mulheres, com as suas visões de mundo, e com as suas interpretações sobre as propriedades das ervas e a sua relação com o corpo e a mente. 
Desse modo, essas vivências constituem os mundos culturais das erveiras, em que há o modo de preparar o chá, de escolher as raízes, o tempo de fervê-las ou colocá-las em infusão, de tomar o chá pelas mãos da mãe que trabalha, pelas mãos da filha que auxilia, enquanto o seu olhar aprende com a mãe, o modo como fazer. Nesses momentos de saber-fazer são expressos modos culturais de convivência aprendidos e transformados ao longo do tempo, visto que a cultura:

é algo que sempre e inevitavelmente estamos criando. Não apenas as coisas da matéria da Terra transformadas em objetos da Vida, mas as tessituras de palavras, de ideias partilhadas que em nós tornam possível o viver e o conviver (BRANDÃO, 2015, p. 111).

Mediante isso, os gestos, as palavras e as ideias compartilhadas nas formas de como saber reconhecer uma raiz, uma folha e se essas apresentam propriedade medicinal, bem como fazer um banho de ervas, expressam os modos de vida culturais de ser erveira, momentos em que ocorrem ensinos e aprendizagens. Sobre esses ensinos e aprendizagens foram destacadas a oralidade, a escuta e a escrita, conforme a Erva-doce recordou e explicou, referente a como aprendeu com a sua mãe:

foi no dia a dia. A mãe foi mostrando "isso é pra isso!" é assim, esse aqui é uma planta, a minha mãe pegou, mostrou, falou e eu aprendi assim. Quando eu comecei a trabalhar com as ervas eu pegava o caderno, anotava tudinho, pra eu poder fazer as garrafadas, poder trabalhar, tanto com ela verde, como ela seca. Eu já trabalhei assim com as ervas como elas estão (verdinhas). Agora eu não trabalho mais com elas assim verdes, só na época das festas (São João, Ano novo). Então, como eu aprendi a manipular, aprendi a usar ela tanto verde, como seca, eu prefiro trabalhar com as garrafadas (ERVADOCE).

Nota-se que esse processo de ensino e aprendizagem entre ela e a mãe, caracteriza-se pelos momentos de mostrar, falar e 
escrever. Desse modo, enquanto a mãe explicava ao "mostrar" e ao "falar", a Erva-doce praticava a observação e a escuta ao que era explicado, para em seguida escrever. Nessa vivência vê-se a gestualidade entre a mãe mediante ao gesto de pegar, mostrar a planta para ensinar e, a filha, referente ao gesto de escrever, para aprender.

Desse modo, caracteriza-se o gesto como uma forma de comunicação entre as duas, as quais demonstram uma à outra, por meio dos seus gestos que estava ocorrendo o processo de ensino e de aprendizagem, pois "o gesto contém forças reveladoras de um poder de persuasão impossível para a palavra. Ele põe em jogo todos os sentidos não só de quem o executa mas também de quem o observa." (SOARES, 2006, p. 111).

Conforme narrado pela Erva-doce, a comunicação por meio da palavra e dos gestos ocorreu no momento de aprendizado vivenciado no dia a dia, ou seja, não havia os dias e as horas marcadas, e somente um lugar específico para ocorrer o ensino e a aprendizagem. Mas, em um dia, hora e local, como na casa dela e no Ver-o-Peso, mãe e filha desenvolviam a sua forma de ensinar e aprender. Sobre como ocorreu este processo de ensino e aprendizagem, a Erva-doce relatou que registrou o que aprendeu com a mãe dela, pois:

eu tenho um caderno que eu anoto tudinho. Por exemplo, eu vou fazer essa garrafada. Então, eu ia escrever tudo o que eu vou usar nela. Eu colocava pra que é, como é tomado, como é feito, pra explicar para o freguês. Assim eu também fui aprendendo. Tudo o que eu vou sabendo eu vou anotando, vou procurando fazer por ali também. Muito já está na mente, eu já não preciso mais do caderninho (ERVADOCE).

Logo, o ato de registrar por meio da escrita, foi uma forma que possibilitou a sua aprendizagem sobre a manipulação das ervas, a qual consiste em saber como o produto deve ser preparado, a sua finalidade e a forma como deve ser utilizado. Além disso, a sua fala demonstra que o registro no seu caderno foi importante também para ela conseguir explicar para o freguês sobre o produto. 
Além dos processos de ensino e aprendizagem vivenciados pelos laços familiares, principalmente materno, os relatos também apresentaram que os ensinos e aprendizagens ocorrem entre os colegas que trabalham no setor das ervas, e em cursos fitoterápicos:

primeiramente foi a mãe que ensinou, porque aqui é de pai para filho e os amigos também ajudam. Se a gente tem dúvida vai com o colega. O colega lá ensina, a gente já faz de uma forma que dá certo e se expande (ERVA-DOCE).

aprendi tudo, o conhecimento como manipular, como fazer os remédios, através das pessoas que sabiam, como a minha mãe e entre os amigos $e$ também o curso fitoterápico que eu fiz (ERVA-DOCE).

Referente à forma geracional de ensino e aprendizagem, essa ocorre com a finalidade de continuidade dos saberes, como observado a seguir:

tudo de bom e eu tento passar pra minha neta, pra ela ir tendo um conhecimento também. Por mais que um dia, eu não sei se ela vem trabalhar aqui. Quando eu estava morando em Mosqueiro e a gente via alguma casca, alguma raiz, alguma erva diferente eu já ia mostrando pra ela e dizendo o significado, pra que serve. As vezes quando vão procurar um remédio lá, ela liga pra mim e diz: 'vovó traz tal coisa!' ela já me liga, ela já sabe (ERVA-DOCE).

Essa forma de ensinar e aprender, entre ela e a neta, desenvolvida no dia a dia, por meio da observação e da oralidade, é semelhante ao modo como Erva-doce aprendeu com a mãe. A oralidade, entendida como relações comunicativas que tem característica interventora, como organizacional, nos diferentes âmbitos onde ocorre, de tal modo que:

a oralidade está em toda parte, porque a conversação se insinua em todo lugar; ela organiza a família e a rua, o trabalho na empresa e a pesquisa nos laboratórios. Oceanos de comunicação que se 
infiltram por toda parte (CERTEAU; GIARD; MAYOL, 2013, p. 337).

Em vista disso, a oralidade constitui processos de ensino e aprendizagem, como o descrito pela Erva-doce, e diz respeito aos objetivos, desejos e necessidades dos sujeitos, como a ação da Ervadoce, de ensinar a neta, mediante à continuidade dos modos de saber-fazer conhecidos e praticados por sua família.

Referente a isso, compreende-se a memória, a oralidade e a gestualidade como aspectos que compõem a expressividade cultural presente nos modos de saber-fazer das erveiras. Por isso, os conhecimentos compartilhados nestes modos de saber-fazer decorrem da relação entre passado e presente; e das narrativas, por meio da oralidade e dos gestos, nos momentos de ensino e aprendizagem vivenciados por elas nos seus cotidianos.

\section{OS SABERES CULTURAIS SOBRE ERVAS MEDICINAIS}

Compreende-se que os sujeitos constroem os seus saberes no contato com o mundo, na partilha de experiências uns com os outros, que envolve além da cognição, o sentir. Nos relatos foi afirmado o ato de sentir, referente ao reconhecimento das ervas, por meio do cheiro, da cor e do formato, de modo que:

tem um monte de casca, formato diferente, só no diaa-dia mesmo pra reconhecer. Pelo cheiro, pela cor e pelo formato (CAMOMILA).

eu conheço o cheiro de cada raiz, de cada folha, de cada semente. Eu conheço o cheiro de cada essência $e$ isso é muito importante pra cada um de nós que trabalha aqui (ALOE VERA).

pelo tato, pelo cheiro, de qualquer forma que ela vier eu conheço ela. Tem mais de mil ervas. Tanto as ervas, quanto as cascas, tem mais de mil. São muitas ervas (ERVA-DOCE).

Nessas três falas, observa-se o sentido do olfato aguçado, diante do cheiro de cada erva. Acerca disso, nota-se que a Camomila 
destaca que esse reconhecimento é possível na experiência diária com as ervas. Aloe Vera aponta que conhecer as ervas é muito importante para o trabalho como erveira. Importância esta que pode ser compreendida a partir da fala da Erva-doce, ao ressaltar que existe mais de mil ervas e cascas.

Desse modo, o corpo toca, sente o formato da folha, o seu cheiro, enquanto a mente evoca a lembrança daquele cheiro e daquele formato, para identificá-la. O corpo, em par com a mente, lembra, reconhece, visto que:

o corpo na verdade é uma memória sábia que registra os sinais do reconhecimento: ele manifesta, pelo jogo das atitudes de que dispõe, a afetividade da inserção no bairro, a técnica aprofundada de um saber-fazer que sinaliza a apropriação do espaço (CERTEAU; GIARD; MAYOL, 2013, p. 53).

Logo, o corpo pela visão, pelo toque, pelo cheiro, manifesta como conhece as ervas e segue a busca de como saber-fazer cada perfume, banho de ervas. Dessa forma, vê-se a importância do ato de sentir, essencial a este saber-fazer, acerca da identificação das ervas. Mediante isso, compreende-se a relação entre saber e sentir, visto que:

há sempre algum saber inscrito no fazer. Talvez aqui devêssemos estabelecer um contraponto necessário entre saber inscrito e saber escrito, entre saber com e saber sobre. Ou, ainda, recuperar o que a etimologia da palavra saber nos indica, qual seja, a relação com o sabor, e assim nos alertando para o saber que precisa do contato, tal como o paladar precisa da língua para sentir o sabor. Enfim, um saber que não se abstraia do contato com o mundo, um saber que precisa sentir (GONÇALVES, 2015, p. 119).

Isto chama a atenção para a compreensão dos atos humanos de conhecer e de saber como processos construídos de forma objetiva e subjetiva, referente a não dicotomia entre corpo e sentimento, que segundo Freire (2001) trata-se da inteireza humana, ao experienciar o mundo, a partir do entendimento que "Sou uma 
inteireza e não uma dicotomia [...] Conheço com meu corpo todo, sentimentos, paixão. Razão também" (FREIRE, 2001, p. 18).

Há, portanto, uma integralidade do sujeito, que envolve corpo, mente, razão, sentimentos. Mediante isso, as erveiras constroem os seus conhecimentos, como, por exemplo, conhecer o poder de cada erva para utilizá-las, como ressaltado a seguir:

só pode misturar as coisas que você conhece. As cascas que você conhece para tal remédio. A gente não pode misturar coisas que a gente não conhece. Você só pode misturar aquela erva que você conhece, não vai misturar erva que você não conhece que não vai dar certo (ERVA-DOCE).

A Erva-doce demonstra que saber-fazer um remédio natural diz respeito a conhecer os recursos naturais utilizados, como as cascas, assim, não se trata do simples misturar. Nesse campo de sabedoria das ervas, é imprescindível conhecê-las para que o remédio funcione como o desejado. Além de conhecê-las, é necessário saber como combiná-las. Para isso, há modos de fazer que dizem respeito à quantidade e ao tempo de preparo, como assinalado a seguir:

na minha infância eu aprendi como manusear cada erva, porque cada erva tem um tipo de preparo e tem que saber, tanto a manusear, como explicar para o cliente porque ela (a erva) pode melhorar, como também, se não souber usar, pode prejudicar, porque em excesso, por exemplo, tudo prejudica. Então tem que saber a quantidade, é tanto para um litro, meio litro, quantas folhas, tudo isso os clientes perguntam (CAMOMILA).

Ao afirmar que existe um tipo de preparo para cada erva, ela lembra a importância do saber manusear, saber explicar a funcionalidade de cada erva e saber quantificar cada elemento utilizado no preparo, para que não haja prejuízos à saúde. Desse modo, esses saberes que ela aprendeu são fundamentais às suas práticas de manusear, de indicar e de responder às dúvidas das pessoas que buscam pelos produtos. Sobre os modos de sabe-fazer 
das erveiras, destacou-se a relação entre corpo e espírito, de modo que:

quando a gente vai manipular um produto natural tu tem que estar preparada para aquilo. Primeiro lugar, o espírito. A higiene, as mãos, rosto, boca, os olhos tem que estar saudáveis. $E$ o ambiente que tu faz o produto, isso é muito importante! Tem que estar com uma áurea boa, porque não pode errar nenhuma medida, nada para não ter nenhum efeito colateral. Então, você tem que estar com uma higiene perfeita, o ambiente limpo, as vasilhas têm que estar combinando. Uma combinação, um conjunto de todos os elementos que vão ser usados, inclusive o elemento principal que é o corpo, pois se o corpo não está bem, a mente não está bem. Se você não está com as mãos bem lavadas, se você não está com o corpo limpo, não dá para manipular nada. Então, corpo, ambiente, utensílios limpos, principalmente o corpo, o ambiente e as ervas, tudo tem que estar impecável. Tem que ter uma boa ventilação também, porque tudo influencia. Não pode fazer nada se tiver estressado, aborrecido, principalmente doente, é melhor nem começar. Tudo interfere, tudo tem a ver (ALOE VERA).

Ao versar sobre o momento em que ela faz os seus produtos, a Aloe Vera ressaltou a combinação de elementos importantes para desenvolver o seu saber-fazer. Acerca disso, há o conjunto dos elementos: corpo, espírito, ambiente e utensílios que compõem esse saber-fazer de manipulação das ervas.

Desse modo, nesse processo se evidencia a relevância da conexão entre o corpo e a mente, vista a afirmação: 'se o corpo não está bem, a mente não está bem', de acordo com o estado de saúde física e sentimental de quem manipula o produto natural. Sobre os produtos naturais, a Aloe Vera demonstra, a exemplo, o preparo dos banhos, de modo que:

um exemplo: tu vai fazer umas trinta garrafas de banho de descarga. No banho de descarga são usados vários tipos de ervas, pode fazer com sete, quatorze ou vinte e uma ervas. Eu costumo fazer o de 
sete ervas. Eu tenho que estar bem para eu fazer esse banho, porque esse banho, além de trazer coisas positivas para mim que é quando eu começo a me concentrar para produzir, ele vai ter que ter o dobro para o cliente. Se a pessoa está com baixa estima, com depressão, com insônia. Chegou o momento dela cuidar do espírito e da alma, por meio de um banho de limpeza e purificação, depois faz uma defumação. Então, quem está produzindo aquilo tem que estar com uma áurea boa para poder passar, vender para aquela pessoa que está com problema. Se você não tiver no positivo, aquilo não vai funcionar para o cliente. Isso na parte espiritual (ALOE VERA).

Nota-se que ela usa a expressão 'estar bem' para fazer o banho. Esse estado diz respeito à ela, de atrair coisas boas para si, no momento em que está concentrada para fazer o banho e a quem irá tomar banho, ou seja, o preparo do banho interfere sobre si mesma e quem está acometido de algum problema corporal e espiritual.

Esse saber-fazer, portanto, apresenta dimensões como o sentir, por meio do corpo e do espírito em momentos, como: o preparo dos produtos, a identificação e a diferenciação das matériasprimas, como as cascas, raízes e folhas.

Esse entendimento de conhecer por meio do corpo, o qual sente, age, comunica, acontece, por exemplo, nos momentos de identificação das ervas e suas propriedades medicinais. Ao olhar as cores, os formatos, ao diferenciar as folhas, as cascas, quanto aos saberes de identificação das ervas, das suas propriedades medicinais e de diferenciação entre as ervas, que ocorre:

pela espécie, pela folha. Cada uma tem as suas características, como há folhas maiores, há folhas menores, tem a cor de cada uma. A Pata-de-vaca (folha), por exemplo, você vai reconhecer ela, porque ela tem o formato igual ao símbolo de uma pata mesmo. [...] O Barbatimão tu vai reconhecer, porque ele é mais vermelhinho, então cada um tem suas diferenças.

por exemplo, a pata de vaca serve para diabetes, para emagrecer, para queimar gordura, quando a pessoa 
está com excesso de gordura no sangue, faz o chá com quatro folhas (CAMOMILA).

Portanto, a cor, o formato das folhas maiores, das menores, compõem as diferenças entre as inúmeras ervas que a Camomila conhece e sabe como prepará-las, transformá-las em chás, como a quantidade exata de folhas, no chá da pata-de-vaca, feito com quatro folhas, como ela ensinou nesse seu relato.

Esses saberes compõem as experiências cotidianas dessas mulheres referentes ao ato de transformarem as ervas em banhos, pomadas, sabonetes, intervém em situações de saúde física e sentimental, desenvolvem as suas formas de trabalho e dinâmicas de ensinos e aprendizagens. Diante disso, entende-se que essas experiências cotidianas apresentam dimensão cultural, pois:
[...] A cultura configura o mapa da própria possibilidade da vida social. Ela não é a economia e nem o poder em si mesmos, mas o cenário multifacetado e polissêmico em que uma coisa e a outra são possíveis. Ela consiste tanto nos valores e imaginários que representam o patrimônio espiritual de um povo, quanto das negociações cotidianas através das quais cada um de nós e todos nós tornamos a vida social possível e significativa (BRANDÃO, 2002, p. 24).

Mediante a isso, compreende-se que a partilha e a criação de saberes caracterizam as atividades culturais que os sujeitos realizam, não somente em relação ao quanto produzem, mas também aos significados que atribuem às suas produções, e interferem sobre os seus cotidianos. Em face disso, os saberes apresentam especificidades vinculadas aos contextos socioculturais em que são compartilhados.

Nesse sentido, nos lugares históricos, socioculturais em que os sujeitos ensinam e aprendem, eles e elas expressam as suas subjetividades e saberes, a serem reconhecidos, por exemplo, na EJA, visto que:

a geografia da EJA é lugar para, então, elaborar um trabalho de reconstrução e legitimação das subjetividades. Nesse espaço se constituem sujeitos com histórias arquitetadas na diversidade e 
multiplicidade de situações que devem direcionar as práticas e propostas da EJA com saberes nascidos do diálogo com estas diferenças (MOURA; SILVA, 2018, p. 19).

Quanto às relações entre os contextos socioculturais com a construção e socialização de saberes, Jovchelovitch (2004, p. 25) destacada que: "há um número infinito de formações sociais que produzem um número infinito de formas diferentes de saber". Essa autora chama a atenção para as dimensões sociais e culturais que formam os processos de saberes, representados pelos sujeitos. Desse modo ela compreende que o saber:

é sempre obra de uma comunidade humana e, portanto, deve ser entendido no plural. Não há uma forma de saber apenas, mas muitas. Essa variação corresponde à variação nas formas de relação social que constituem tanto o saber como a comunidade. Daí que o saber é uma forma plástica e heterogênea, cuja racionalidade e lógica não se definem por uma norma transcendental, mas devem ser avaliadas em relação ao contexto psicossocial e cultural de uma comunidade (JOVCHELOVITCH, 2004, p. 28).

Logo, chama-se a atenção para o fato de que a essência de cada saber está vinculada aos distintos contextos socioculturais em que este é compartilhado. Isso quer dizer que o ato de saber está relacionado às concepções políticas, religiosas, estéticas que norteiam as formas de convivência entre os sujeitos.

Segundo Albuquerque (2015) todo o saber está inscrito em uma ordem cultural e diz respeito aos modos como os grupos criam e recriam os seus cotidianos socioculturais. Concernente a isso:

pode-se, assim, associar os saberes culturais a expressões como saberes do cotidiano, saberes da experiência, saberes sociais - gestados no cotidiano de vida e de trabalho [...] Como todo o agir humano, esses saberes dependem de uma ordem cultural local posto que diferem de sociedade para sociedade, de uma geração à outra, bem como 
diferem em suas regras de ação e seus modos de proceder, razão pela qual são históricos e sujeitos à mudança (ALBUQUERQUE, 2015, p. 655).

Diante disso, nota-se o caráter mutável destes saberes, mediante os contextos históricos, geográficos, religiosos, nos quais emergem. Segundo Oliveira (2016, p. 23):

os saberes culturais, entendemos como os produzidos nas práticas sociais e culturais e que refletem formas de viver, pensar e compreender o mundo, valores, imaginários e representações. Eles são diversos, multirreferenciais e constituídos por magmas de significações, de relações, de conteúdos e práticas culturais.

Diante dessa ponderação, depreende-se que os saberes culturais se constituem nas relações entre os sujeitos em interface com o ambiente em que vivem, convivem e transformam e nesta dinâmica de convivência constroem os seus processos identitários.

Nesse sentido, por exemplo, tem o reconhecimento como ser erveira vinculado aos saberes que elas produzem e compartilham, bem como ao modo como elas significam os seus cotidianos, de acordo com as suas concepções estéticas, religiosas, anunciadas nas suas produções e organizadas da seguinte forma:

aqui tem a parte mística que são as simpatias e tem a parte medicinal. A parte medicinal que são as garrafadas, as pomadas, e têm os cremes para a pele, de Copaíba, de Andiroba, de Castanha-do-Pará. Na parte mística tem os banhos, banho atrativo, de descarga, pra sorte, têm os perfumes, as essências, os sabonetes, defumações. O medicinal são as pomadas, garrafadas, óleos, shampoos (ALOE VERA).

Essa distribuição de cunho místico e medicinal dos produtos evidencia a variedade e criatividade do saber-fazer das erveiras expressado no setor das ervas, que o caracteriza como um lugar onde se encontram produtos para atender a inúmeras questões de saúde física e sentimental. 
Portanto, compreende-se que o caráter educativo dos modos de saber-fazer das erveiras está presente nas vivências delas, a partir de como ensinam e aprendem nos seus cotidianos, sobre as propriedades medicinais das ervas. Essas mulheres sabem reconhecer as propriedades medicinais de cascas, raízes e folhas, sabem diferenciá-las, sabem como combiná-las e fazer os banhos de ervas e as garrafadas, além de saberem indicar chás para a saúde e bemestar. Os ensinos e as aprendizagens vivenciados por essas mulheres são expressões culturais das suas convivências, nos âmbitos tanto familiar quanto do trabalho, haja vista a afirmação das suas autonomias de ser erveira.

\section{CONSIDERAÇÕES FINAIS}

Os atos de ensinar e aprender que constituem a dimensão educativa construída nos cotidianos dessas mulheres que protagonizaram este trabalho ocorrem por meio da oralidade, do registro escrito, da observação, da gestualidade, da escuta em que acontecem as comunicações e dos diálogos. Saberes são compartilhados como reconhecer uma raiz, uma folha e se estas apresentam propriedade medicinal, como fazer um banho em momentos vivenciados no dia a dia, em que se ensina e aprende em casa, no convívio familiar e em diferentes gerações.

Concernente a isso, a expressão 'cotidianos educativos', é referente aos saberes e fazeres vivenciados pelas erveiras e diz respeito ao experienciar, isto é, praticar os banhos, tomar os chás e as garrafadas, nos ambientes e convívios familiares. Por isso, dentre as vivências relatadas pelos sujeitos, observou-se um banhar-se de aprender, o qual consiste na própria vivência do sujeito.

No caso dos modos de saber-fazer das erveiras, as vivências cotidianas de ensino e aprendizagem não são todas somente para atender as atividades econômicas e a formação para a profissão como erveira. Uma vez que, há as situações, conforme já pontuadas, das aprendizagens em convívio familiar, conforme o objetivo de se compartilhar uma sabedoria como herança familiar, em vista da reexistência desta, da sua continuidade ao longo dos anos, por diferentes gerações, a partir da combinação entre receitas e modos 
como cada uma experiencia o que aprendeu e ensina, recria técnicas e combinações de ervas medicinais.

\section{REFERÊNCIAS}

ALBUQUERQUE, M. B. B. Educação e saberes culturais: apontamentos epistemológicos. In: PACHECO, A. S.; NASCIMENTO, G; SILVA, G. S; MALCHER, M.A. (Orgs.). Pesquisas em estudos culturais na Amazônia: cartografias, literaturas e saberes interculturais. Belém: EditAEDI, 2015.

BARDIN, L. Análise de conteúdo. São Paulo: Edições 70, 2011. BONDÍA, J. L. Notas sobre a experiência e o saber de experiência. Revista Brasileira de Educação, n. 19, p. 20-28, 2002. BOSI, E. Memória e Sociedade: lembranças de velhos. 3. ed. São Paulo: Companhia das Letras, 1994.

BRANDÃO, C. R. A educação como cultura. Campinas: Mercado de Letras, 2002.

BRANDÃO, C. R. Nós, os humanos do mundo à vida, da vida à cultura. São Paulo: Cortez, 2015.

BRANDÃO, C. R. A pergunta a várias mãos: a experiência da partilha através da pesquisa na educação. São Paulo: Cortez, 2003.

CERTEAU, M. de; GIARD, L.; MAYOL, P. A invenção do cotidiano: 2. Morar, Cozinhar. RJ: Petrópolis, Vozes, 2013.

FELDMANN, M. G.; NUNE, A. L. P.; MIRANDA, H. P. Cultura e Interculturalidades na EJA. Revista Internacional de Educação de Jovens e Adultos, v. 3, n. 6, p. 156-170, jul./dez. 2020.

FREIRE, P. À sombra desta mangueira. 4. ed. São Paulo: Olho D'Água, 2001.

GARCIA, N. M.; YUNES, M. A. M.; CHAVES, P. F.; SANTOS, L. O. dos. Educando Meninos e Meninas: Transmissão geracional da pesca artesanal no ambiente familiar. Psicol. Educ. [online], n. 25, p. 93112. ISNN. 1414-6975. 2007. 
GONÇALVES, C. W. P. A globalização da natureza e a natureza da globalização. 6 ed. Rio de janeiro: civilização brasileira, 2015. JOVCHELOVITCH, S. Psicologia social, saber, comunidade e cultura. Revista Psicologia \& Sociedade, v. 16, maio/ago, 2004. MINAYO, C. de S. Ciência, técnica e arte: o desafio da pesquisa social. In: MINAYO, C. de S. (org.); DESLANDES, Suely; CRUZ NETO, Otavio; GOMES, Romeu. Pesquisa social: teoria, método e criatividade. 21 ed. Petrópolis, RJ: Vozes, 1994.

MINAYO, C. de S. Trabalho de Campo: contexto de observação, interação e descoberta. In: MINAYO, C. de S; DESLANDES, Suely; GOMES, Romeu. (Orgs.). Pesquisa social: teoria, método e criatividade. 28 ed. Petrópolis, RJ: Vozes, 2009.

MOURA, C. B. de; SILVA, M. P. da. O sujeito da EJA. In: GARCIA, R. M; MOURA, C. B. de; SILVA, M. P. da (Orgs.). EJA, diversidade e inclusão: reflexões impertinentes. João Pessoa: Editora da UFPB, 2018.

OLIVEIRA, I. A. de; FONSECA, M. J. C. F.; SANTOS, T. R. L. dos. A entrevista na pesquisa educacional. In: MARCONDES, M. I; TEIXEIRA, E.; OLIVEIRA, I. A. (Orgs.). Metodologias e técnicas de pesquisa em educação. Belém: EDUEPA, 2010.

OLIVEIRA, I. A.de; MOTA NETO, J. C.da. A Construção de categorias de análise na pesquisa em educação. In: OLIVEIRA, I. A.; MARCONDES, M. I; TEIXEIRA, E. (Org.). Abordagens teóricas e construções metodológicas na pesquisa em Educação. Belém: EDUEPA, 2011.

OLIVEIRA, I. A. de. Epistemologia e Educação: bases conceituais e racionalidades científicas e históricas. Petrópolis: RJ: Vozes, 2016.

SOARES, C. L. (Org.). Corpo e História. Campinas, SP: Autores Associados, 2006.

Submetido em: Junho/ 2021.

Aceito em: Agosto/ 2021. 